Type of the Paper (Article.)

\title{
Processing and testing of a novel superstructural material
}

\author{
Alejandro Pereira ${ }^{1 *}$, Alberto Tielas ${ }^{2}$, Teresa Prado ${ }^{1}$, Maria Fenollera ${ }^{1}$ and José Antonio Pérez ${ }^{1}$ \\ 1 Manufacturing Engineering Group (GEF) EEI Campus Lagoas, University of Vigo, 36310 Vigo, Spain. \\ 2 Materials Department. Centro Tecnológico de la Automoción de Galicia (CTAG). Polígono Industrial A \\ Granxa, 36475 Porriño (Pontevedra). Spain. \\ * apereira@uvigo.es
}

\begin{abstract}
The need to develop novel lightweight materials and their manufacturing processes is sets out to meet the new aerospace, automotive and construction requirements. Within this context, this research work is proposed to develop a novel thermoplastic composite material with high mechanical properties. These composites will be based on thermoplastic matrixes made from polyamide and $35 \%$ short glass fiber filled-polyamide reinforced with different types of fabrics. As reinforcement, glass fiber fabrics will be used as the base. They will be treated with different processes, both chemical and physical, to promote adherence to the matrix. Textile overmoulding technology was selected for manufacturing these composites. This technology was primarily developed to manufacture aesthetic lined components and has achieved a great implantation. Once these new composites are manufactured, they will be submitted to different tests to evaluate their behavior regarding adhesion, impact strength and stiffness. It is expected an improvement on stiffness and impact absorption.
\end{abstract}

Keywords: PA66, PA66GF, weaves, reinforcement, overmoulding, composites

\section{Introduction}

The demand of thermoplastic materials has suffered a high increase in the last 30 years due to the growth of their possible applications [1], both as new products and as substitution materials, including metals. Their low cost, good thermal and mechanical performance and their low specific weight have contributed in a great way.

However, thermoplastics have some limitations in their use, particularly in applications with higher mechanical requirements and higher prices that are mainly used in the aerospace sector and, in special cases, in the automotive sector, such as PEEK (Polyetheretherketone). Due to the higher price and difficulties of processing, these materials are not usually used in the automotive sector, only in some specific applications [2-3]. Recently, the use of additive manufacturing technology with thermoplastic matrix has been gaining attention in aviation or space industry. The use of dry textile fabrics infiltrated in a highpressure resin transfer process is postulated as a viable alternative of low cost and high production ratio necessary in sectors such as automotive [4].

To overcome these limitations, these materials are reinforced, for example, with glass fibers allowing to obtain better mechanical and thermal properties. These improvements of properties largely depend on the adhesion on the matrix-fiber interface, the orientation and the proportion of reinforcing fiber. Although there are already fiber-reinforced thermoplastics for injection processes, in these types of applications, the fibers in the materials are often shorts and their orientation cannot be controlled during processing [5]. This does not allow taking advantage of all the properties as is done in other plastics manufacturing processes, such as fabric reinforced thermosets [6].

In the field of building materials, reinforced textile membranes have been increasing their use in recent years. Nowadays traditional strengthening of building structures is often replaced with modern textile reinforcement. The selection of a membrane for struc- 
tural purposes has various criteria such as mechanical properties, insulation, light transmission, fire retardancy, foldability, and cost. PVC (polyvinylchloride)-coated PET (polyethylene terephthalate) fabric is one of the most common commercially available types [7].

Mikolajczyk et al. [8], investigated building composite beams made from Mapei Mapefill concrete reinforced with knitted meshes, made using the technology of warp knitted fabrics. Three variants of knitted technical meshes made of polyamide PA6, PP (polypropylene) and fibreglass threads were used as reinforcement. Regarding the mechanical properties, in case of the composite with fiberglass, strength properties were twice better compared to the original concrete beam.

Textiles in prefabrication as well as in the retrofitting of existing concrete or masonry structures was studied by Triantafillou et al. [9]. Fiber rovings arrange in two or more directions are used. Textiles with polymers improves the stability of the textile material and the mechanical interlock between the textile and the matrix. As a result, the stiffness, the ultimate flexural or shear capacity, and the performance under serviceability loads are increased. In addition, cracking is better controlled.

Franke et al. [10], formed composite construction parts, specifically sandwich materials, with good load-bearing characteristics. Performed composites of pure PA66 and PTFE (polytetrafluoroethylene), PTFE-PA66 compounds with a PA66 injection matrix and glass fiber reinforced core, resulting compounds with high mechanical strength.

Composite materials, mainly fiber-reinforced polymers, are nowadays used in many applications in which lightweight, high modulus and specific mechanical strength are critical issues [11-12]. A major challenge is also to ensure that these substitute materials can be recyclable like the thermoplastics in order to produce new products for a more sustainable future.

Fiorotto's team from the University of Padua has investigated the manufacturing of a thermoplastic with a reinforcement sheet of a thermoformed fiber, which is inserted in the mold and, right after the thermoplastic is injected. It produces an economic composite with good technical qualities. Adhesion parameters between the fiber and the polymer have been experimentally investigated [13].

Khondker's team has experimented the injection molding with textile inserts of knitted polyethylene fabric as reinforcement and only polyethylene as matrix. Since they are similar elements, there would be a high bond between matrix and reinforcements. In addition, an impregnation of a resin in the textile was applied. As a result, they found that the tensile properties were dependent on the impregnated resin [14].

Yang et al. has investigated the impact of PP composites, reinforced with fibers of the same PP, and of PP reinforced with knitted glass fiber (GF). Panels of these composites are made using the injection-compression molding technique, studying the behavior depending on the composites temperatures. It was demonstrated that the impact strength of $\mathrm{PP} / \mathrm{PP}$ and GF/PP was very similar [15].

In the University of Zaragoza, the injection on fabric has been investigated from the aesthetic point of view, studying the injection pressure parameters inside the mold in order to achieve a good final finish. The methodology to determine the relationship between pressure and flow has been studied, with the aim to optimize this process. With that purpose they have designed a spiral mold with pressure sensors and three types of textiles with different qualities and different foam thicknesses [16].

The German company "BASF" has developed a material called "Ultramid Estructure ${ }^{\circledR}$ ". It is a long glass fiber-reinforced polyamide in the form of sheets. This product represents a significant advance in performance. The exceptional feature of the composites manufactured with long glass fiber-reinforced plastic components is the three-dimensional fiberglass net that they form during the conventional injection molding, which gives the product exceptional physical properties, both at high and low temperatures. The fiber net forms the skeleton of the component which lasts even after calcination. This structure is the reason why warping, plastic deformation behavior and energy absorption in this type of material have a performance close to metals [17]. 
After performing an analysis of the investigations in the field of polymeric materials, it can be summarized that there are several researches in the experimental field of addition of various elements such as natural and non-natural fiber-reinforcements with varied bases, like, for example, in PP and PET. However, there are not sufficient studies or profuse clear results on PA matrix, hence the objective of this project is oriented to work with PA and reinforcement PA with fiberglass, which is widely used in the automotive, aerospace and infrastructure industry.

\section{Materials and Methods}

The methodology developed in this work for the consecution of the reinforced composite material is based on the phases shown in Figure 1. First, the materials for the matrix and the reinforcing ones are selected, the latter being manufactured in the form of fabric. In order to corroborate the material compatibility between the matrix and the reinforcing materials, their melting points are validated by a differential scanning calorimetry test. Also, to verify if the manufacturing process damaged the fabrics, a tensile test of the manufactured fabrics is performed. After that, the composite samples are manufactured by combining the matrix and reinforcement materials. Finally, these samples are tested to validate their properties.
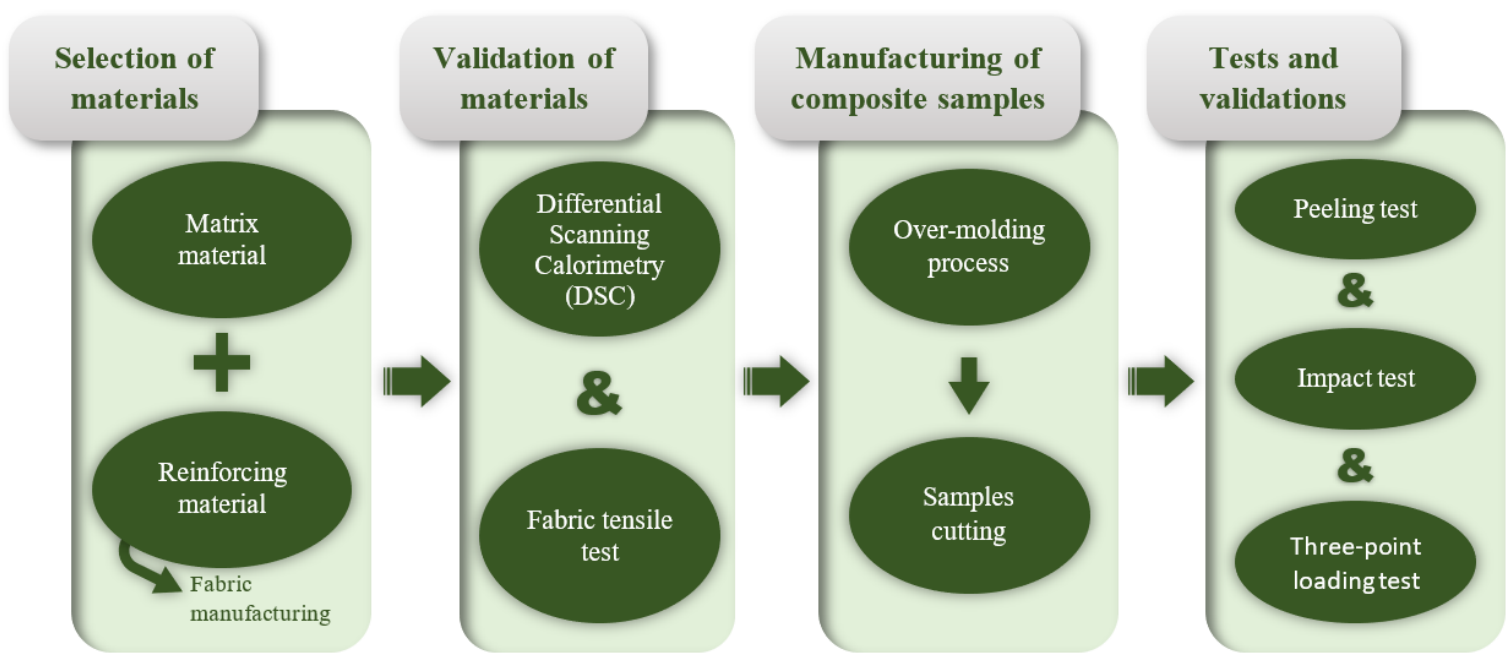

Figure 1. Experimental procedure.

In the manufacturing of composite samples, the injection over-molding process has been chosen. In this process a piece of fabric is placed between the plates of the mold and a matrix material is injected to reinforce the superstructural material (Figure 2). 


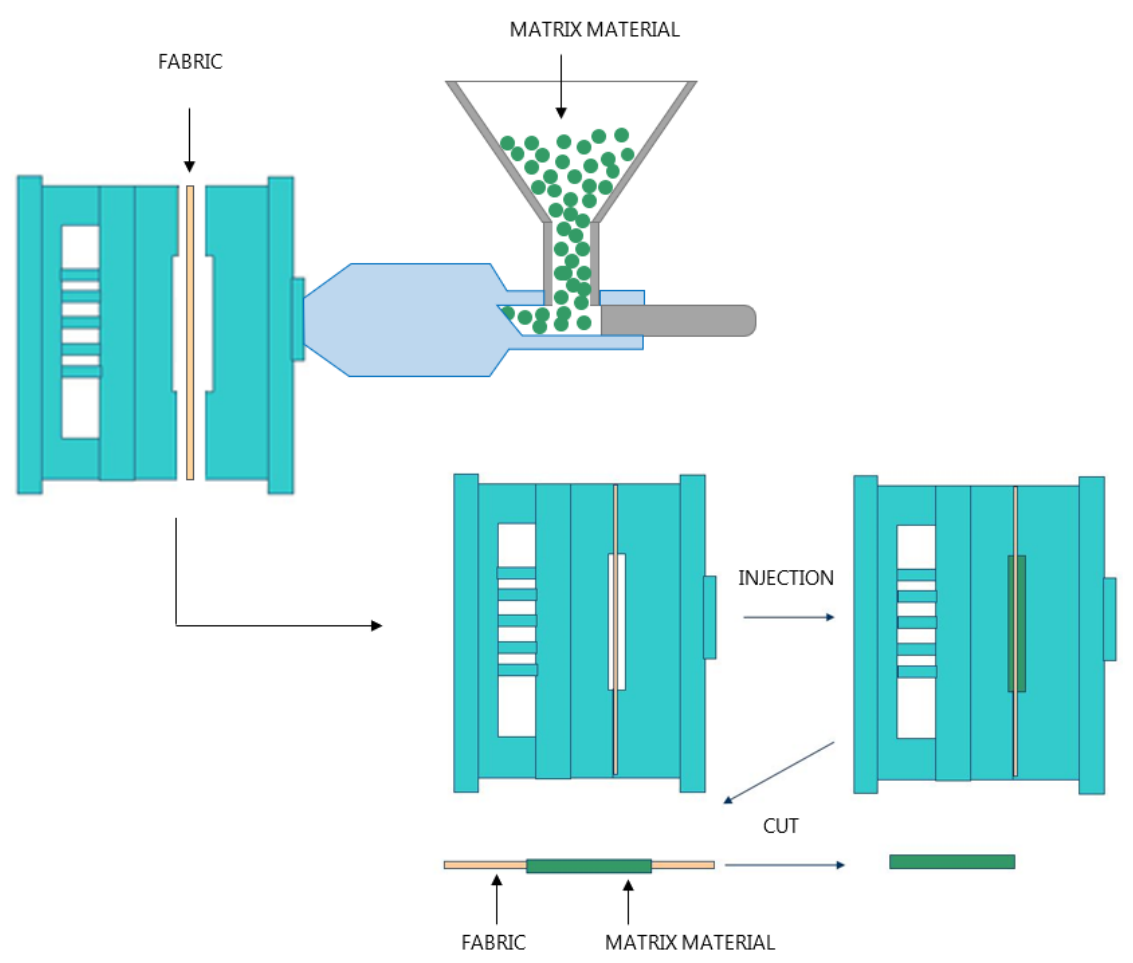

Figure 2. Injection over-molding process sketch.

\subsection{Materials selection}

Two types of materials should be selected as discussed above, the matrix and the reinforcement materials. These materials must be chemically compatible, so that the matrix helps to stiffen the fabric.

\subsubsection{Matrix materials}

PP and PA are the most widely thermoplastics introduced in the automotive sector $[6,18-19]$. The first ones are used for general parts while the second ones are used for parts with more restrictive mechanical requirements. Since the goal of this work is to develop a thermoplastic composite material with high mechanical properties, PA is finally the selected material.

After an exhaustive benchmarking analysis of commercial PA, and weighting their mechanical, physical ant thermal properties, two PA66 have been chosen as the base matrix material, whose properties are shown in Table 1:

- Zytel® 70G35HSL NC010 reinforced with $35 \%$ short GF (PAGF).

- Zytel® 101L NC010 non reinforced (PA).

Table 1. Mechanical and physical properties of selected materials.

\begin{tabular}{ccc}
\hline Properties & PA & PAGF \\
\hline Density $\left(\mathrm{g} / \mathrm{cm}^{3}\right)$ & 1.14 & 1.41 \\
Young's modulus $(\mathrm{GPa})$ & 1.4 & 8.30 \\
Bending modulus $(\mathrm{MPa})$ & 1,210 & - \\
Impact resistance - Charpy-V-notch $(\mathrm{J} / \mathrm{m})$ & 110 & 15 \\
Poisson's ratio & 0.41 & - \\
\hline
\end{tabular}

\subsubsection{Reinforcement materials}

From the side of the fabrics, and due to the lack of suppliers in the market for hybrid fiberglass fabric with PA, this material was obtained by manufacturing processes. For the manufacture of the hybrid fabrics, two different techniques were studied:

1. Over-stitching manufacturing of PA thread on fiberglass fabric.

2. Manufacture by weaving of hybrid fabrics, with fiberglass on a prototype loom. 


\section{Over-stitching manufacturing}

To produce de fabric by over-stitching, it is necessary to select the weight and orientation of the fabric fibers since these features affect the greater or lesser opening of the mesh (Figure 3).

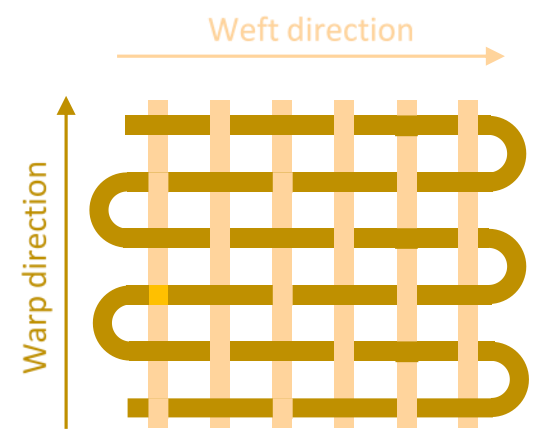

Figure 3. Fabric structure.

The more open the mesh, the better the embedding of the thermoplastic in the fabric (Figure 4) and consequently the better the adhesion at the matrix-fiber interface.
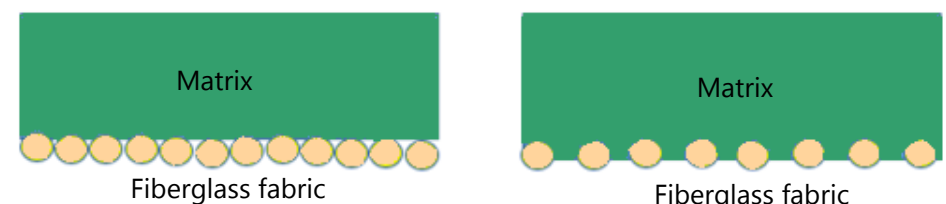

Figure 4. Embedding schema.

Regarding the orientation of the fibers in the fabric, a multidirectional fabric $\left(0^{\circ} / 90^{\circ}\right)$ was chosen to minimize the anisotropy of the properties of the composites.

Keeping these orientations as a basis, fabrics with lower weights were selected for the processing since they have a bigger pitch between threads. Two fiberglass fabrics with weights of 86 and $125 \mathrm{~g} / \mathrm{m}^{2}$ with different mesh opening were selected to manufacture by over-stitching (Table 2):

- $\quad$ Fiberglass of $86 \mathrm{~g} / \mathrm{m}^{2}$ (GF86).

- $\quad$ Fiberglass of $125 \mathrm{~g} / \mathrm{m}^{2}$ (GF125).

Table 2. Characteristics of the fiberglass fabrics.

\begin{tabular}{ccccc}
\hline \multirow{2}{*}{ Characteristics } & \multicolumn{2}{c}{ GF86 } & \multicolumn{2}{c}{ GF125 } \\
& Weft & Warp & Weft & Warp \\
\hline Fiber percentage & 49 & 51 & 53 & 47 \\
Fiber type & EC9 34 & EC9 34 & EC9 34X2 & EC9 34X2 \\
Number of threads per cm & 12.0 & 12.5 & 9.6 & 9.0 \\
\hline
\end{tabular}

To facilitate the ulterior injection over-molding process, a PA fabric that acts as a coupling agent between the fiberglass fabric and the matrix, was added. To stitch both fabrics it was used a PA thread (Figure 5). Both PA fabric and PA thread are made of PA66, the same material as the base, which ensures the chemical compatibility and helps to stiffen the fiberglass fabric in the process of over-stitching. 


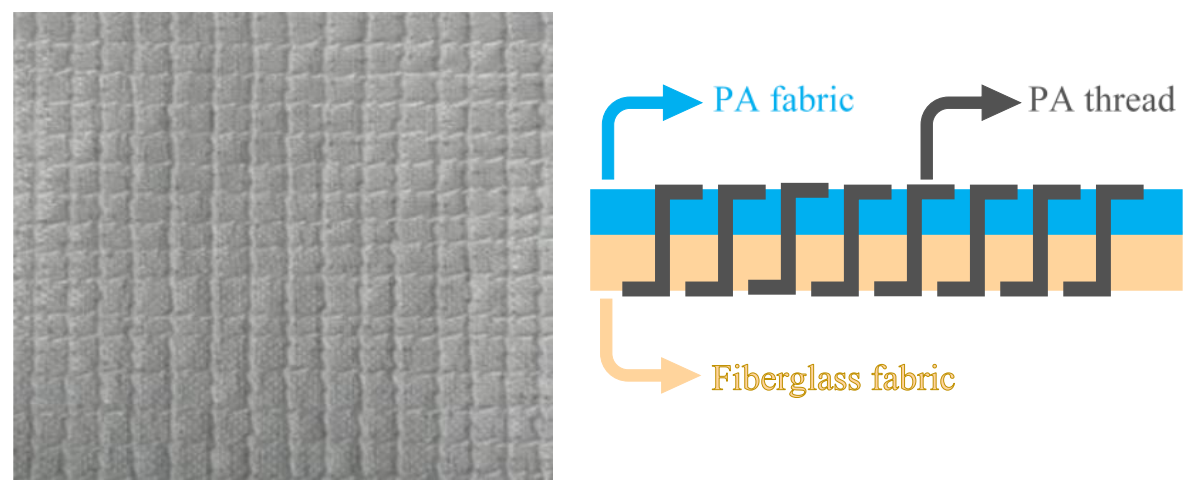

Figure 5. Hybrid fabric constitution.

Characteristics of the PA fabric and PA thread are shown in Table 3 and Table 4 respectively.

Table 3. Characteristics of the PA fabric. Monodur® from Cadisch Precision Meshes.

\begin{tabular}{cc}
\hline Characteristiccs & PA fabric \\
\hline Weight $\left(\mathrm{g} / \mathrm{m}^{2}\right)$ & 110 \\
Filament diameter $(\mu \mathrm{m})$ & 210 \\
Mesh opening $(\mu \mathrm{m})$ & 500 \\
\hline
\end{tabular}

Table 4. Characteristics of the PA thread. Passat20 from Hicoman.

\begin{tabular}{cc}
\hline Characteristics & PA thread \\
\hline Diameter $(\mathrm{mm})$ & 0.50 \\
Linear density (TEX) & 179.92 \\
Resistance (N) & 108.50 \\
Deformation (\%) & 29 \\
\hline
\end{tabular}

As a result of the over-stitching process two hybrid fabrics are obtained:

- $\quad$ Fiberglass + PA thread by over-stitching of $86 \mathrm{~g} / \mathrm{m}^{2}$ (PAGF86).

- $\quad$ Fiberglass + PA thread by over-stitching of $125 \mathrm{~g} / \mathrm{m}^{2}$ (PAGF125).

Weaving manufacturing

For the fabrics manufactured with fiberglass on a prototype loom (Figure 6), a singleend roving for long fiber thermoplastics PA composites SE 4535 from 3B Fibreglass was selected (Table 5). The proprietary sizing chemistry is specifically engineered to provide excellent wet out, optimum resin-fibre load transfer and adhesion for exceptional mechanical performances.

Table 5. Fiber characteristic from 3B Fibreglass.

\begin{tabular}{cc}
\hline Characteristics & Fiber \\
\hline Density $\left(\mathrm{g} / \mathrm{cm}^{3}\right)$ & 2.62 \\
Linear density $(\mathrm{TEX})$ & 1200 \\
Filament diameter $(\mu \mathrm{m})$ & 17 \\
\hline
\end{tabular}




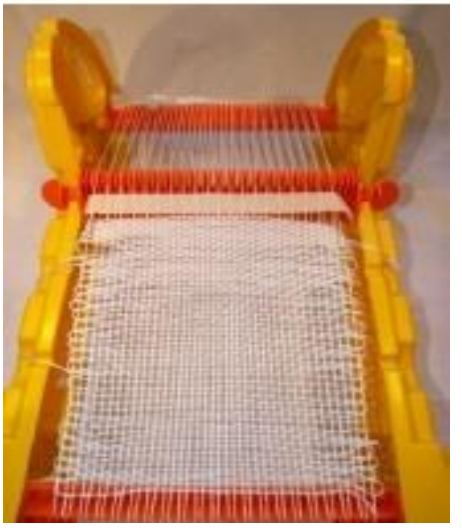

(a)

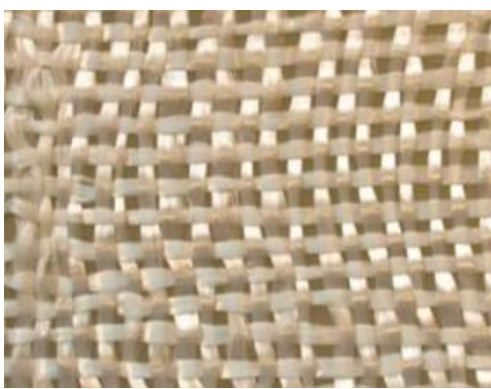

(b)

Figure 6. (a) Prototype loom. (b) Fiberglass fabric.

A hybrid fabric composed by fiberglass roving with PA thread was also created. The procedure for making this hybrid fabric is the same as for the fabric made with only fiberglass, with the difference that, in this case, for each horizontal fiberglass thread two PA66 threads are interspersed (Figure 7).

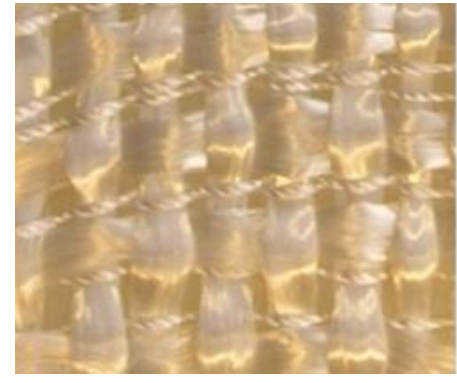

(b)

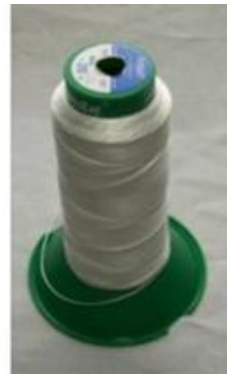

(b)

Figure 7. (a) Fiberglass + PA hybrid fabric. (b) Polyamide reel of thread.

These two fiberglass fabrics were functionalized with aminopropyltriethoxysilane (APS) to provide them with new properties [20-23], obtaining the following fabrics to the tests:

- $\quad$ Functionalized fiberglass (GFF).

- $\quad$ Functionalized fiberglass + PA thread (GFFPA).

\subsection{Validation of materials}

Before manufacturing the composites, differential scanning calorimetry (DSC) tests were performed in order to validate the melting point of the thermoplastic materials referred in the manufacturers' datasheet (fabric, textile thread and granules for the injection) and to stablish a correlation between the melting points of the PA threads and fabrics and the PA pellets to be injected. The tests were carried out on a previously calibrated "DSC Perkinelmer precisely" equipment, according to specifications of the standard ISO 113571:2017 [24]. Three samples of each material (PA66 fabric, PA66 thread, PA matrix and PAGF matrix) were tested resulting in 12 tests.

Once the fabrics were manufactured, to assess whether the manufacturing process damaged the fabrics, a tensile test on these fabrics was performed on an Instron 4505 universal testing machine at room temperature $\left(23^{\circ} \mathrm{C}\right)$ with a $1 \mathrm{KN}$ load cell and a constant speed of $50 \mathrm{~mm} / \mathrm{min}$ until failure, according to specifications of the standard ISO 5274:1997 [25]. These processing conditions have a direct influence on the morphological structure of the parts [26-27], and this structure, in turn, influences the properties of the 
material [28]. This test was not performed with functionalized/hybrid fabrics because no comparison values are available. With this test it was sought that the maximum force supported by the hybrid fabric was at least equal to or greater than the force supported by the GF/PA fabric. Then, three samples of each material (PA66 fabric, PA66 thread, GF86, GF125, PAGF86 and PAGF125) were tested resulting in 18 tests.

\subsection{Manufacturing of composite samples by over-molding process}

For the injection of the composites, an Engel 350 ton injection mold machine with a $60 \mathrm{~mm}$ diameter screw and a mold with flat plates was used. Both the equipment and the mold are not adapted for injection by the injection-compression process. The mold is also not prepared for the manufacturing of samples by a multipoint or sequential injection process, consequently it was not possible to apply these techniques in order to reduce the injection pressure during the process. The fabric was placed directly in the cavity of the movable plate. It was fixed by a double-faced tape at each of the corners and in the middle of the fabric longitudinal distance in order to ensure the total support of the fabric (Figure $8)$.

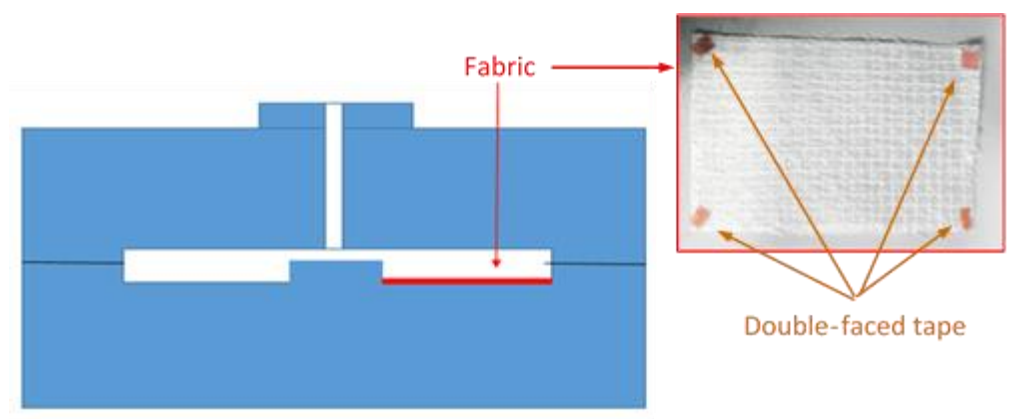

Figure 8. Fixing system of fabric to the mold.

Fourteen samples were injected considering the different combinations of matrix and reinforcement materials, corresponding to the design of experiments that is shown in Table 6 .

Table 6. Design of experiments.

\begin{tabular}{cccc}
\hline Matrix & $\begin{array}{c}\text { Fabric } \\
\text { (Reinforcement material) }\end{array}$ & Sample acronym & Number \\
\hline PA & None & PA & 1 \\
\hline PAGF & None & PAGF & 2 \\
\hline PA & GF86 (conventional fabric) & PA-86 & 3 \\
& GF125 (conventional fabric) & PA-125 & 4 \\
\hline PAGF & GF125 (conventional fabric) & PAGF-86 & 5 \\
& GF86 (conventional fabric) & PAGF-125 & 6 \\
\hline PA & PAGF86 (over-stitched fabric) & PA-PA86 & 7 \\
& PAGF125 (over-stitched fabric) & PA-PA125 & 8 \\
& GFF (weaved fabric) & PA-F & 9 \\
& GFFPA (weaved fabric) & PA-FPA & 10 \\
\hline PAGF & PAGF86 (over-stitched fabric) & PAGF-PA86 & 11 \\
& PAGF125 (over-stitched fabric) & PAGF-PA125 & 12 \\
& GFF (weaved fabric) & PAGF-F & 13 \\
& GFFPA (weaved fabric) & PAGF-FPA & 14 \\
\hline
\end{tabular}

Figure 9 shows an explanatory diagram of the samples' composition. 


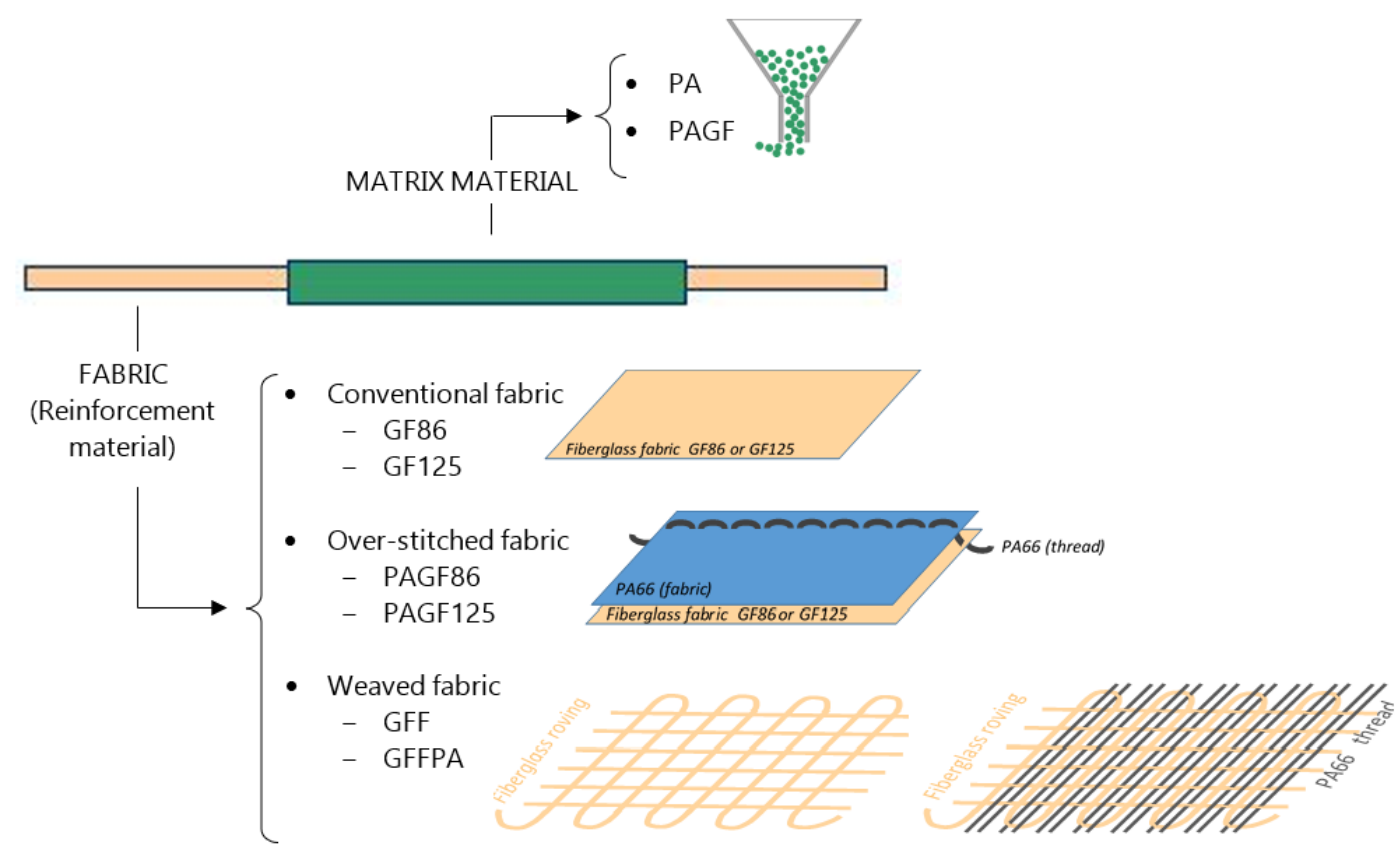

Figure 9. Explanatory diagram of the composition of the samples.

The processing conditions were selected following the manufacturer's recommendations, which essentially depend on the matrix material. Table 7 shows these conditions. Due to the typical hygroscopicity of PA, it was necessary to perform a drying process prior to the injection process, which was carried out in a Koch Technik KKTT55 dehumidifier at $80^{\circ} \mathrm{C}$ for 4 hours, as recommended by the manufacturer.

Table 7. Injection conditions.

\begin{tabular}{ccc}
\hline Condition & PA & PAGF \\
\hline Melt temperature $\left({ }^{\circ} \mathrm{C}\right)$ & 290 & 310 \\
Mold temperature $\left({ }^{\circ} \mathrm{C}\right)$ & 50 & 90 \\
Injection speed $(\mathrm{m} / \mathrm{s})$ & 43 & 44 \\
Clamping force (ton) & 100 & 100 \\
\hline
\end{tabular}

Sample preparation plays a major role in recorded test results. Depending on the geometry and the type of test, different shapes are proposed for cutting the 3 types of samples (Figure 10) [29].

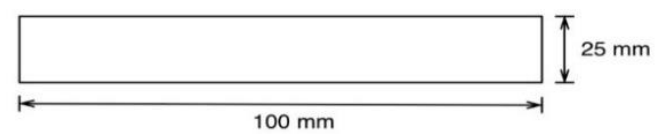

(a)

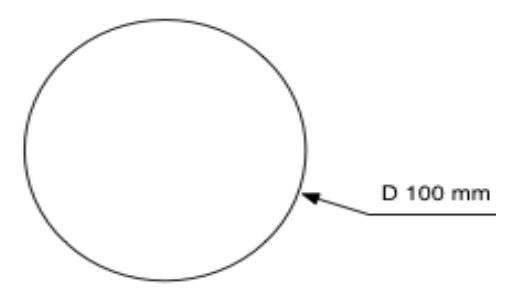

(b)

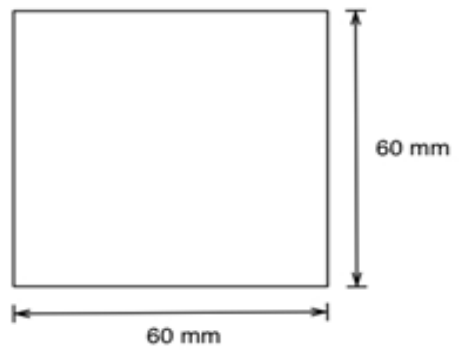

(c)

Figure 10. (a) Tensile and peeling tests. (b) Three-point loading test. (c) Impact test.

\subsection{Tests and validations}


The morphological structure influences the properties of the material, so before realizing the tests in the different samples to evaluate the composites, it was evaluated the shell-core-shell type morphology of them due to the injection process. In Figure 11 it can be observed the asymmetry in the morphology resulting from the difference in the cooling velocity on the side of the fabric with respect to the side without fabric. On the injection side (side without fabric), due to the better thermal conductivity of the mold insert material, the cooling velocity is higher, which causes a well-defined layer. On the other hand, on the ejector side (side with fabric) due to the low thermal conductivity of the fabric, the cooling velocity is much lower than the injection side one, leading to a decrease of the shell advantaging the nucleus formation [30].

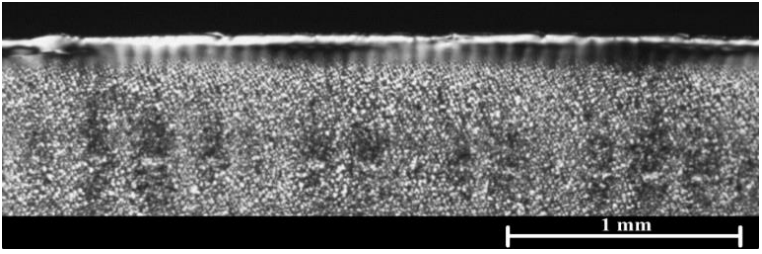

(a)

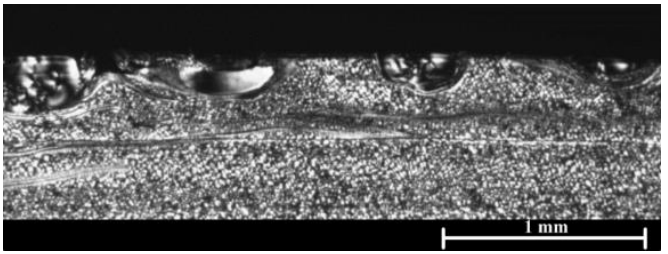

(b)

Figure 11. Morphological structure. (a) Injection side. (b) Ejector side.

In order to evaluate the function of the diverse fabrics used and final reinforced composite, numerous tests were performed. Table 8 summarizes all the test performed to verify each property.

Table 8. Test performed to different composit4es.

\begin{tabular}{ccc}
\hline Function to verify & Test & Quantity \\
\hline Adhesion & Peeling test & 36 \\
Impact strength & Impact test & 42 \\
Stiffness & Three-point loading test & 30 \\
\hline
\end{tabular}

Once the composites have been manufactured by injection, three tests are conducted to assess their behavior. To evaluate the adhesion of the fabrics to the matrix, the peeling test was performed according to ISO 11339 [31]. Tests were carried out on the previous universal testing machine at room temperature $\left(23^{\circ} \mathrm{C}\right)$ with a $1 \mathrm{KN}$ load cell and a constant speed of $50 \mathrm{~mm} / \mathrm{min}$. Three samples of each composite (PA-86, PA-125, PAGF-86, PAGF125, PA-PA86, PA-PA125, PA-F, PA-FPA, PAGF-PA86, PAGF-PA125, PAGF-F and PAGFFPA) were tested resulting in 36 tests. For the manufacturing of the samples for the peeling test, a part of the plate was covered with aluminium adhesive tape, to avoid the adhesion and to be able to use that area for pulling, as shown in the figure 12.

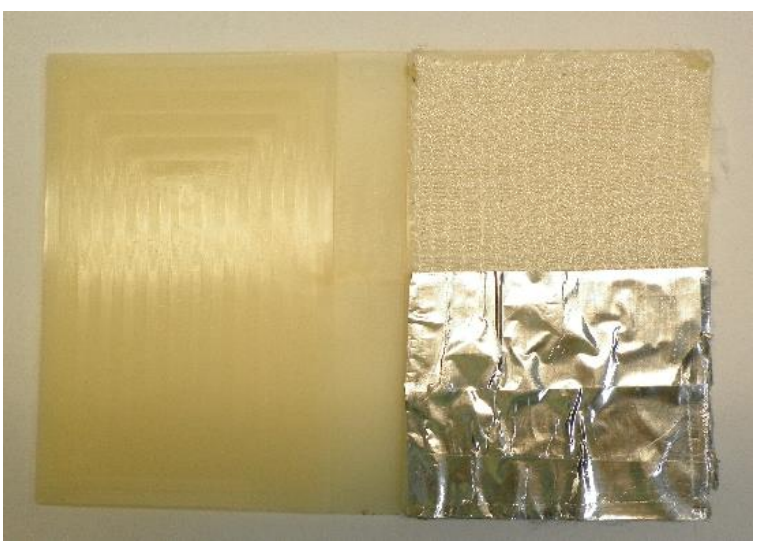


Figure 12. Prototype part for the manufacturing of the peeling test sample.

To determine the influence of the hybrid fabric on the impact properties with respect to the initial matrix, impact tests were carried out in a Fractovis Plus machine using a drop weight instrument at room temperature $\left(23^{\circ} \mathrm{C}\right)$ with a weight of $5.045 \mathrm{Kg}$, a dart with a 20 $\mathrm{mm}$ diameter ball tip, dropping from a 1 meter height [32-33]. Samples with fabrics without reinforcement and samples with the hybrid fabric were tested. The composites were tested with the face of the fabric under impact and with the face of the matrix under impact as shown in figure 13, due to the different morphological structure commented before. Three samples of each composite at both sides (PA-PA86, PA-PA125, PA-F, PA-FPA, PAGF-PA86 and PAGF-PA125) and three samples of the two matrix material (PA and PAGF) were tested resulting in 42 tests. PAGF-F and PAGF-FPA were not tested because of poor adhesion between matrix and fabric.

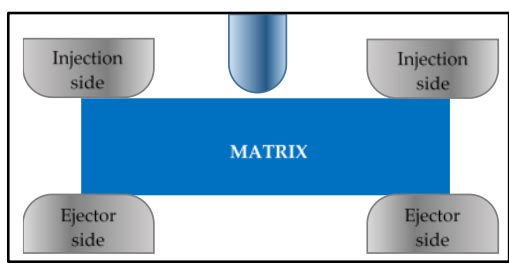

(a)

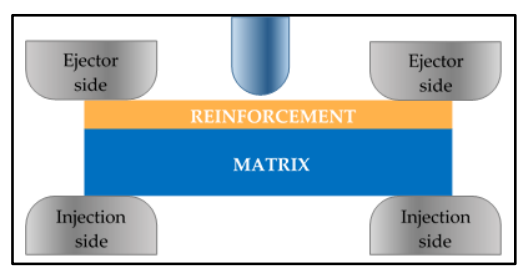

(b)

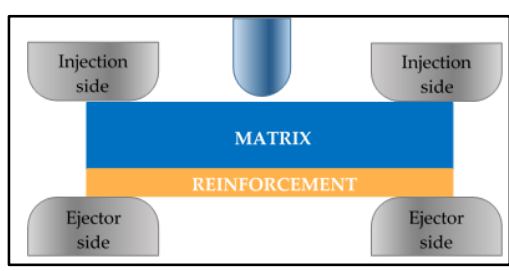

(c)

Figure 13. (a) Sample without fabric reinforcement. (b) Reinforced sample, ejector side. (c) Reinforced sample, injection side.

The three-point loading test used was the one proposed by Hostal and Stevens [34], where the sample is supported in three uniformly distributed points inserted in a circumference with a diameter of $9.35 \mathrm{~cm}$. The load is applied in the center with constant speed, in the same way as in the dart drop impact test. The composites were tested positioned on both sides according to Figure 14. Tests were carried out on the same universal testing machine at room temperature $\left(23^{\circ} \mathrm{C}\right)$ with a $1 \mathrm{KN}$ load cell and a constant speed of 5 $\mathrm{mm} / \mathrm{min}$ up to $2 \mathrm{~mm}$ maximum deformation. Three samples of each composite at both sides (PA-PA86, PA-PA125, PA-F, PA-FPA, PAGF-PA86, PAGF-PA125, PAGF-F and PAGF-FPA) and three samples of the two matrix material (PA and PAGF) were tested for each load orientation, resulting in 30 tests.

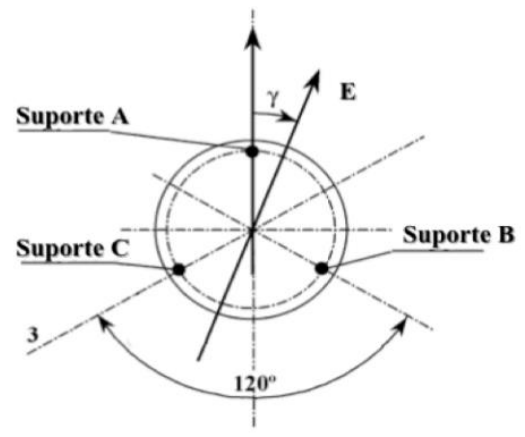

Figure 14. Three-point loading test schema [35].

\section{Results and Discussion}

\subsection{Differential scanning calorimetry (DSC) tests}

The DSC curves of the heat flow vs. the temperature were obtained for the analyzed samples, obtaining graphs similar to the example in Figure 15 for one of the PA matrix material sample. 


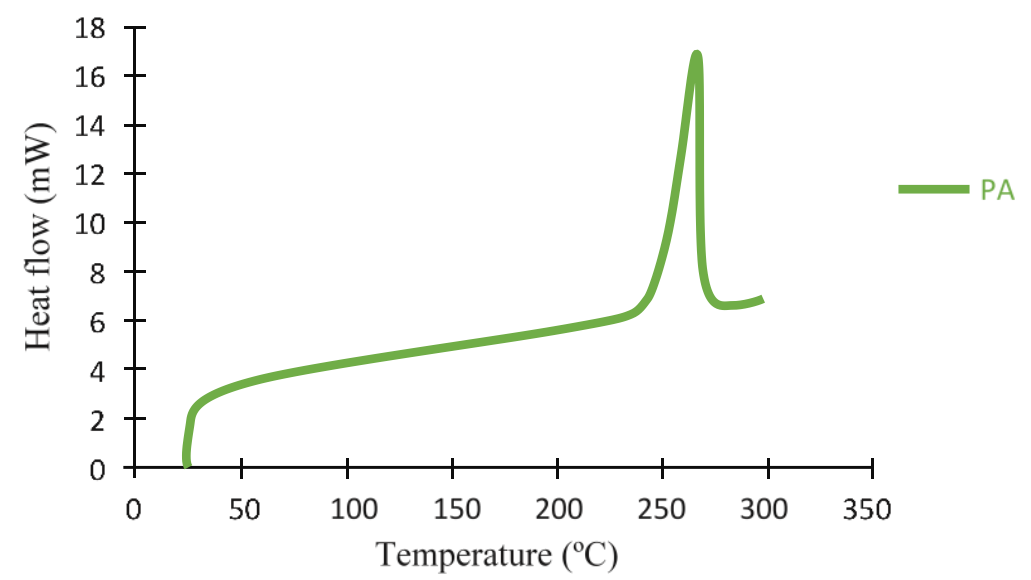

Figure 15. PA matrix material DSC test results.

In the different DSC tests, it was checked that the melting temperature, experimentally measured in the samples, corresponds to that shown by the manufacturers in their datasheets, with variations under $0.5 \%$. It was also verified that all the materials have similar melting temperatures (Table 9), the largest difference being $5.5^{\circ} \mathrm{C}$ between the PA66 textile thread and the PA matrix material, which shows the stability of these materials and the stability of the transitions.

Table 9. DSC test results.

\begin{tabular}{cccc}
\hline \multirow{2}{*}{ Material } & \multicolumn{3}{c}{ Melting temperature (Peak) $\left({ }^{\circ} \mathbf{C}\right)$} \\
\cline { 2 - 4 } & \multicolumn{2}{c}{ Experimental } & Datasheet \\
\hline PA & $\overline{\boldsymbol{X}}$ & $\mathbf{S}$ & 262 \\
PAGF & 263.87 & 1.38 & 262 \\
PA66 thread & 263.21 & 1.51 & - \\
PA66 fabric & 262.59 & 0.95 & - \\
\hline
\end{tabular}

\subsection{Tensile test}

As an example of the graphs obtained from the tensile tests, Figure 16 shows the graph Load vs. Extension of the hybrid fiberglass + PA thread by over-stitching of $86 \mathrm{~g} / \mathrm{m}^{2}$ (PA86 hybrid fabric) compared with its component materials (GF86, PA fabric and PA thread).

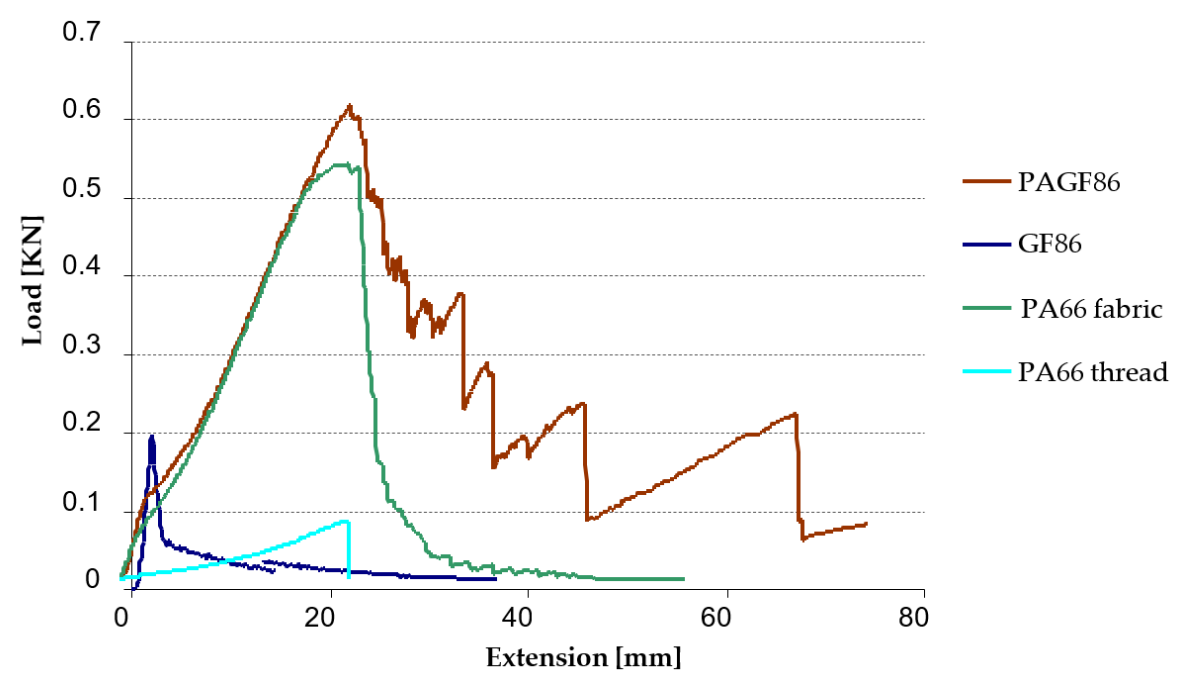


Figure 16. Tensile test curve of PA86 hybrid fabric compared with its components.

The graph shows that the maximum force supported by the hybrid fabric is greater than its components. In Table 10 the values of maximum force obtained for all the material are resumed. It can be observed that the tensile strength of GF125 fabric is higher compared to the tensile strength of the GF86 fabric. In hybrid fabrics this difference does not exist, assuming similar values. This fact is justified by the use of the PA fabric in the manufacture of the hybrid fabrics, since the value of the maximum force recorded for the hybrid fabrics practically corresponds to the value obtained in the PA66 fabric test. It means that the manufacturing process by industrial over-stitching does not influence on the properties of the hybrid fabrics, thus guaranteeing the viability of the manufacturing process.

Table 10. Tensile test results.

\begin{tabular}{ccc}
\hline \multirow{2}{*}{ Material } & \multicolumn{2}{c}{ Maximum force (KN) } \\
\cline { 2 - 3 } & $\overline{\boldsymbol{X}}$ & $\mathbf{s}$ \\
\hline GF86 & 0.19 & 0.03 \\
GF125 & 0.42 & 0.03 \\
PA66 fabric & 0.59 & 0.04 \\
PA66 thread & 0.08 & 0.01 \\
PAGF86 & 0.58 & 0.03 \\
PAGF125 & 0.59 & 0.02 \\
\hline
\end{tabular}

\subsection{Peeling test}

Table 11 shows the mean peel strength of the samples tested. During the tests it was revealed that in the samples reinforced with conventional fiberglass fabric, the fabric is evenly pulled off. However, in the samples based on hybrid fabrics, elaborated both through sewing and weaved by a weaving machine, there are areas in which the adhesion is higher than the reinforcement, thus when performing the test, the fabric is stretched until it breaks.

Table 11. Peeling test results.

\begin{tabular}{ccc}
\hline \multirow{2}{*}{ Sample } & \multicolumn{2}{c}{ Mean peel strength (N/cm) } \\
\cline { 2 - 3 } & $\overline{\boldsymbol{X}}$ & $\mathbf{s}$ \\
\hline PA-86 & 45.33 & 18.9 \\
PA-125 & 34.66 & 3,055 \\
PA-PA86 & 44 & 3.46 \\
PA-PA125 & 44.66 & 9.45 \\
PA-F & 29.74 & 6.9 \\
PA-FPA & 32.89 & 7.4 \\
PAGF-86 & 17.33 & 7.02 \\
PAGF-125 & 25.33 & 5.33 \\
PAGF-PA86 & 26.66 & 3.05 \\
PAGF-PA125 & 22 & 3.46 \\
PAGF-F & No adhesion \\
PAGF-FPA & No adhesion \\
\hline
\end{tabular}

From these results it can be observed that the adhesion load is higher for the samples with matrix without fiberglass (PA matrix) than that of the filled ones (PAGF matrix). This could be due to any kind of chemical incompatibility between the matrix filled with glass fiber and the reinforcement, apart from being the resin denser, which significantly worsens the impregnation of the reinforcement. 
However, analyzing in more detail the graphs of Figure 17 that compare the results of the samples with hybrid fabrics with those with conventional fiberglass fabrics, it can be observed that although the mean peel strengths are similar, the adhesiveness remains longer.

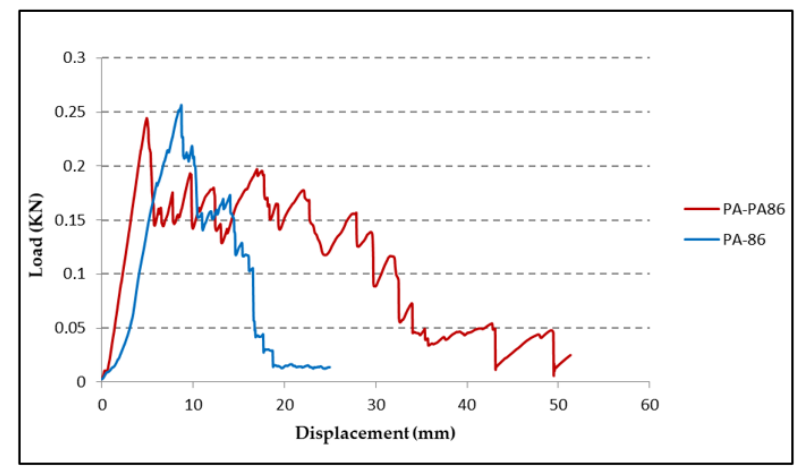

(a)

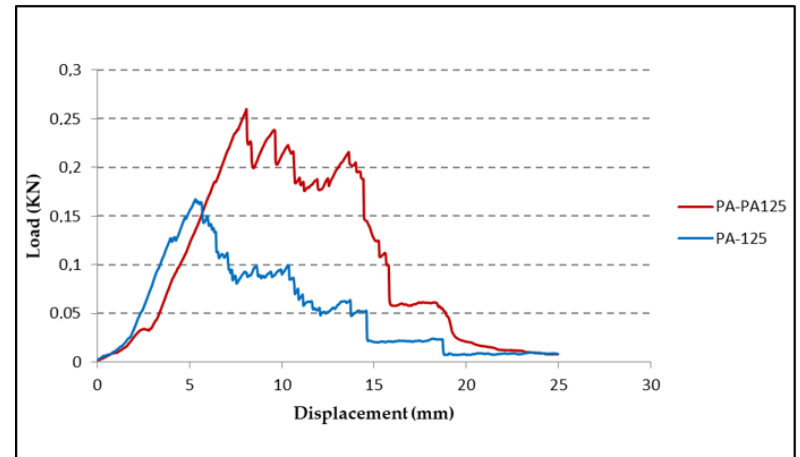

(c)

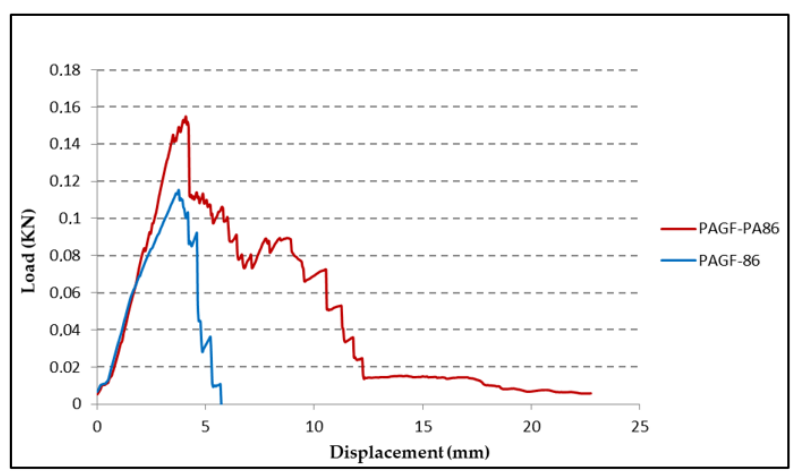

(b)

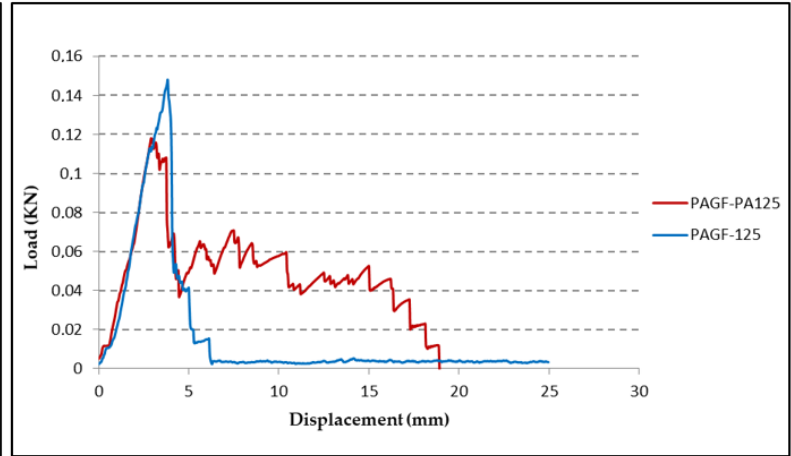

(d)

Figure 17. Comparison of peeling test results between conventional fiberglass fabrics and hybrid fabrics. (a) PA matrix + GF86. (b) PAGF matrix + GF86. (c) PA matrix + GF125. (d) PAGF matrix + GF125.

It can be explained by observing in Figure 18 the total impregnation of the PA thread in the matrix, which confirms that PA thread improves the adhesion between the reinforcement and the matrix.

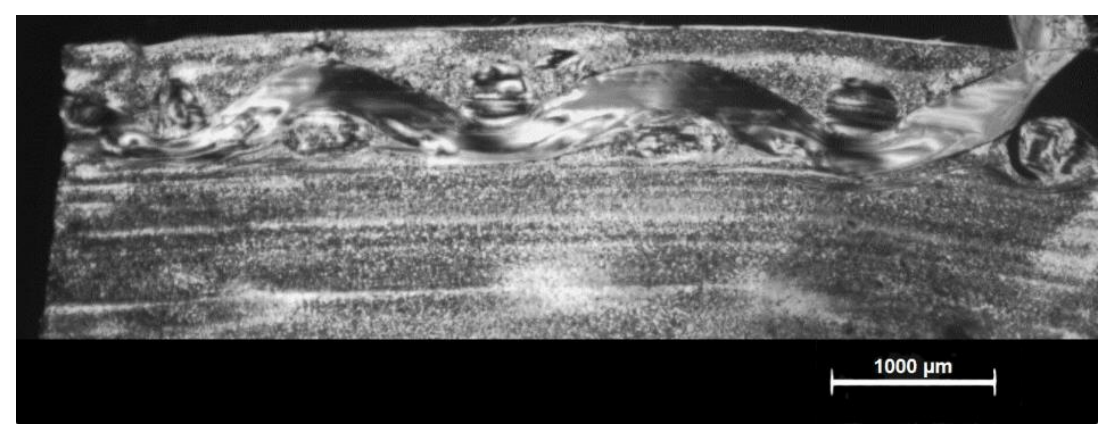

Figure 18. Impregnation of the PA thread in the PA matrix.

The samples with reinforced matrix material and functionalized fiberglass reinforcement fabrics (PAGF-F and PAGF-FPA) finally did not undergo peeling test because the fabric could detach simply pulling by hand. On the other hand, the samples with weaved fabric to reinforce the PA66 matrix are the ones that obtain the worst results. Based on these results and given the difficulty and slowness of making these fabrics, it is considered that the properties of samples with weaved fabrics will no longer be evaluated. 
As described above, the impact test was performed on both sides of the samples and on a sample without fabric reinforcement. The results of these tests are shown in Figure 19. In each graph, the behaviour on each side of the sample is compared to the sample of the matrix material (red line). It was observed that in the case of the PA matrix (Figure 19 $a$ and $b$ ), the behaviour of the composite is worse than that of the matrix. Furthemore, since the impact on the side of the fabric reinforcement (yellow line) is produced on a more rigid area, the rigidity is higher than when the impact occurs on the matrix side (blue line). In the latter case, a ductil behavior is more present at the beginning, with a longer duration of the impact. This behaviour is interesting but does not improve that of the matrix material. However, in the case of PAGF matrix (Figure $19 \mathrm{c}$ and d), the working of the composite is similar to that of the matrix, mainly when the impact is on the side of the reinforcement.

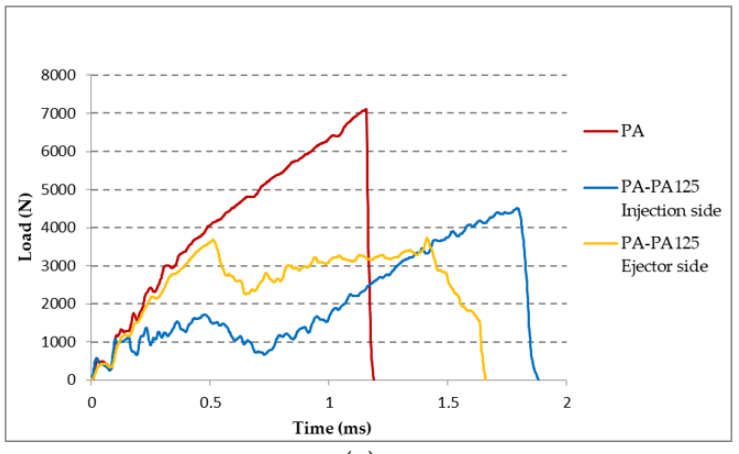

(a)

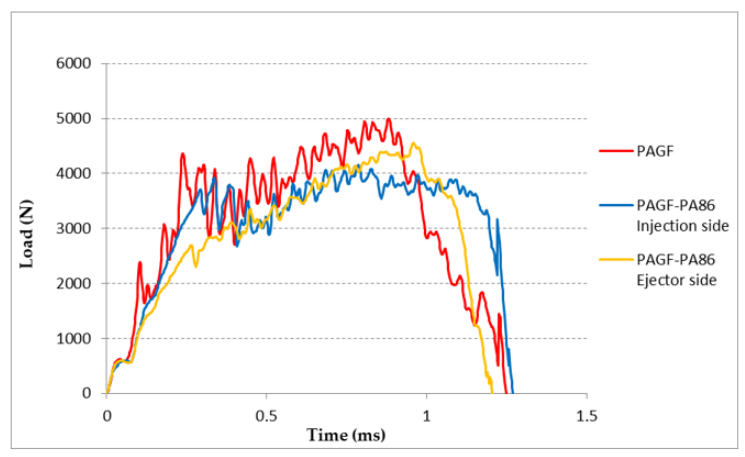

(c)

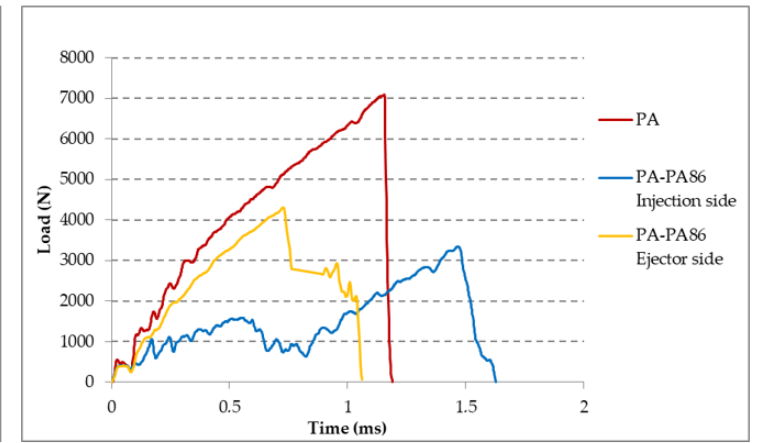

(b)

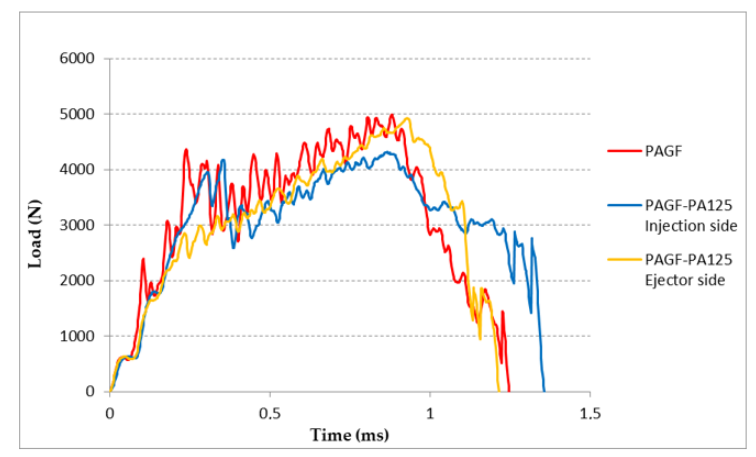

(d)

Figure 19. Comparison of the impact test according to the impact side on the sample and with respect to the matrix material without reinforcement. (a) PA matrix and PA-PA86 reinforcement. (b) PA matrix and PA-PA125 reinforcement. (c) PAGF matrix and PAGF-PA86 reinforcement. (a) PAGF matrix and PAGF-PA125 reinforcement.

From the point of view of the type of fracture, it was observed on the graphs that PA matrix material register only radial fracture while PAGF matrix material reveal both radial and circunferencial fracture (Figure 20). This is due to the greater rigidity and anysotropy of PAGF compared to PA. 


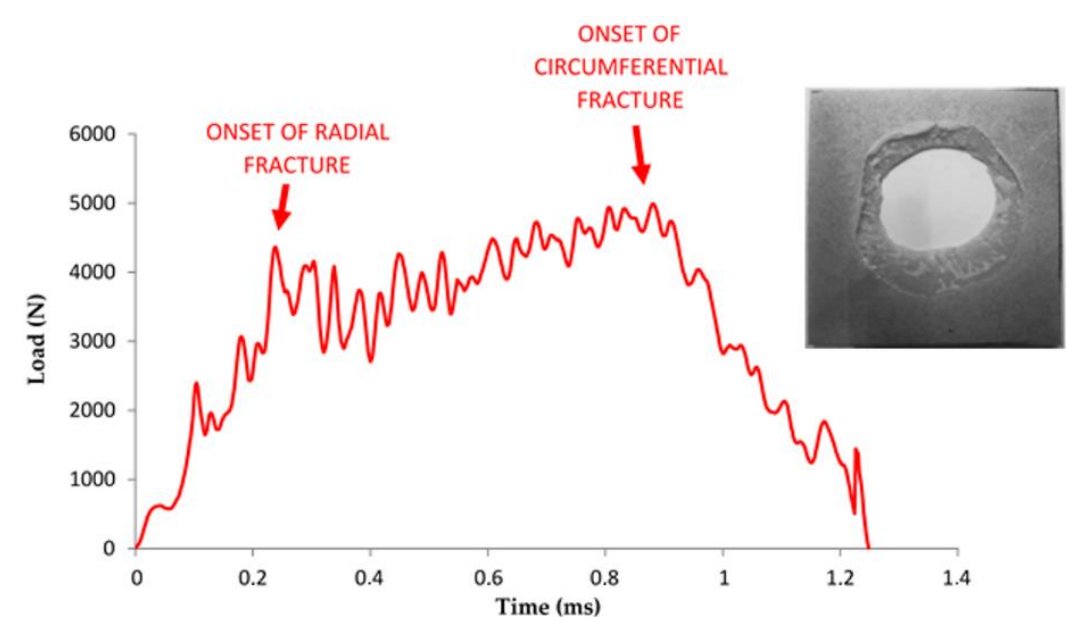

Figure 20. Correlation between fracture propagation and the Load vs. Time for PAGF matrix material.

If both sides of the impact on PA-PA86 samples are analysed, it is observed that on the opposite side of the impact the fractures are developed in a radial direction, which corresponds to a radial fracture evidenced by the curve registered (yellow line in Figure $19 \mathrm{a}$ ). A well-defined whitish circle is observed in Figure $21 \mathrm{~b}$ as a result of the deformation suffered by the sample at the moment of the impact of the dart. Furthermore a higher resistance of the composites is observed when they are impacted on the side of the reinforcement (Figure $21 \mathrm{a}$ and $\mathrm{b}$ ). When the samples impacted on the injection side are analysed, it is detected that beyond appearance of radial fractures, circumferencial fractures occur. In figures $21 \mathrm{c}$ and $\mathrm{d}$, the formation of the radial fracture is distinguished and the subsequent circumferential delamination.

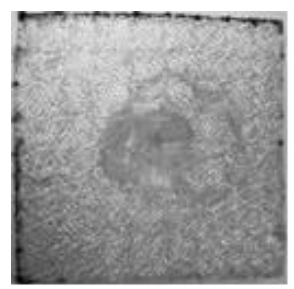

(a)

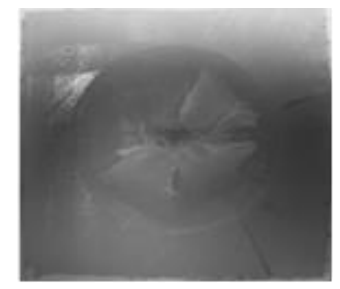

(b)

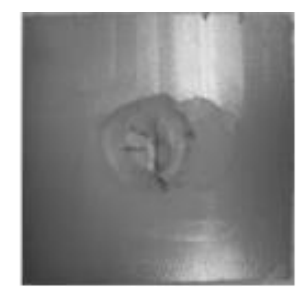

(c)

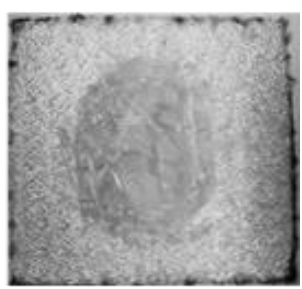

(d)

Figure 21. Impact samples on PA-PA86 composite. (a) Impact face on sample with ejector side impact. (b) Opposite impact face on sample with ejector side impact. (c) Impact face on sample with injection side impact. (b) Opposite impact face on sample with injection side impact.

Similarly, analyzing both sides of the impact on PAGF-PA86 samples, it is noticed the fracture begins with radial cracks and then evolve to circumferential ones with a manifest pattern of rigid material (Figure 22). This is due to the high rigidity material of its base, since it is reinforced with short fiber.

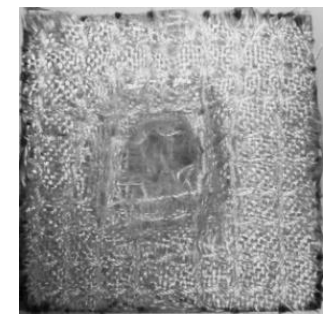

(a)

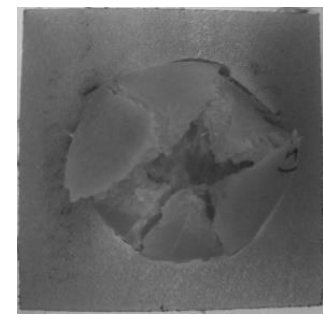

(b)

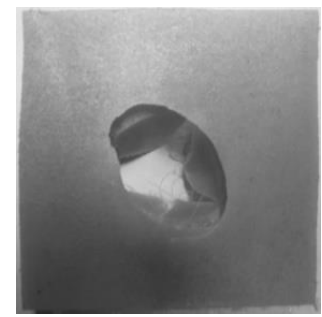

(c)

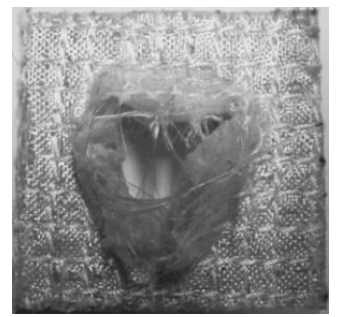

(d)

Figure 22. Impact samples on PAGF-PA86 composite. (a) Impact face on sample with ejector side impact. (b) Opposite impact face on sample with ejector side impact. (c) Impact 
face on sample with injection side impact. (b) Opposite impact face on sample with injection side impact.

\subsection{Three-point loading test}

Regarding the three-point flexural test, the samples are not tested until breakage, thus only their behavior in elastic mode was registered. In the Figure 23, it is verified that none of the composites show a positive gain, that is to say, the properties of the composites registered lower flexural stiffness that their respective matrices. This loss of flexural stiffness was more notable for the composites with PAGF matrix. It can be considered that the lower adhesion of the fabric to the PAGF matrix with respect to the PA, contribute to the decrease of the flexural stiffness.

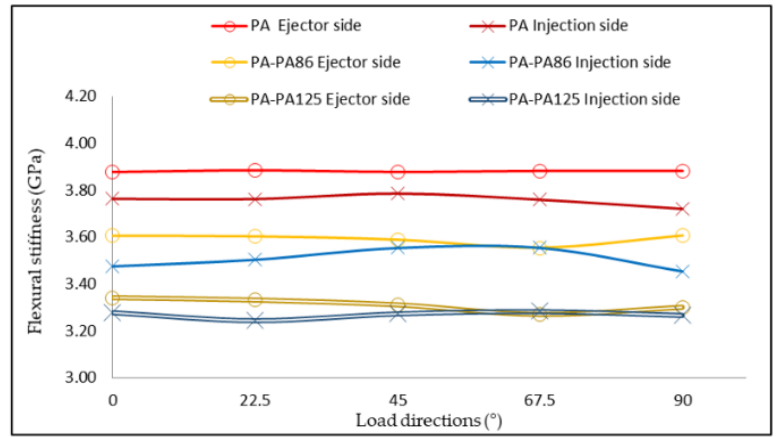

(a)

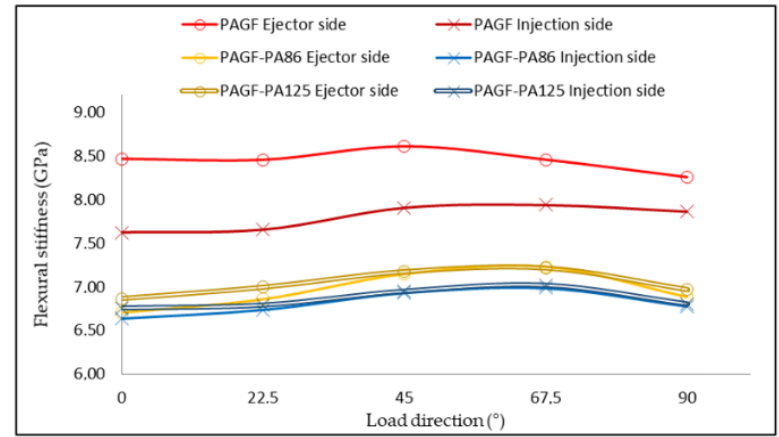

(b)

Figure 23. Comparison of flexural test results according to the impact side on the sample between composites and matrix material without reinforcement. (a) PA matrix. (b) PAGF matrix.

\section{Conclusions and perspectives}

To summarize the results obtained, the properties of each of the composites analyzed in the different tests performed is listed in table 12:

Table 12. Overview of the composites analyzed.

\begin{tabular}{ccccccc}
\cline { 2 - 6 } & $\begin{array}{c}\text { Fabric } \\
\text { manufacturing }\end{array}$ & $\begin{array}{c}\text { Composite } \\
\text { manufacturing }\end{array}$ & Deformation & Peeling & $\begin{array}{c}\text { Impact } \\
\text { strength }\end{array}$ & Stiffness \\
\hline PA-PA86 & Good & Good & Good & Good & Poor & Fair \\
PA-PA125 & Good & Good & Good & Good & Poor & Poor \\
PA-F & Fair & Good & Good & Poor & - & - \\
PA-FPA & Fair & Good & Good & Poor & - & - \\
\hline PAGF-PA86 & Good & Good & Good & Good & Fair & Poor \\
PAGF-PA125 & Good & Good & Good & Good & Fair & Poor \\
PAGF-F & Fair & Good & Good & Poor & - & - \\
PAGF-FPA & Fair & Good & Good & Poor & - & - \\
\hline
\end{tabular}

After analyzing the results, the following conclusions were obtained:

- Regarding the manufacture of the fabric, the one that seems the most industrially viable, taking into account the materials currently available at the market, is the overstitching technology.

- The fabric placement system is considered critical regarding the manufacturing phase of the composites.

- The proposed fixing system has allowed the fabric to rest on one of the cavities of the mold, in order to avoid problems and favor the consolidation of the part, even being a totally manual system.

- It has been proven that this over-molding technology induces a peculiar and asymmetric morphological structure in the materials. The analysis of the morphological 
structure of the composites, by means of reflection microscopy, showed that the low thermal conductivity of the hybrid fabrics induced an asymmetry in the morphological structure of the composites, caused by the lower cooling velocity on the side of the fabric, with respect to the injection side.

- Peeling tests prove that the use of hybrid textiles on the polyamide matrix allows to improve the adhesion on the matrix-fabric interface. The worst adhesion appears between the hybrid fabrics and PAGF matrix. This is mainly due to the higher viscosity of this matrix and the fact that the glass fiber filler already has its own coupling agents that could be not compatible with the fabric.

- With respect to the stiffness tests, it can be ensured that the polyamide matrix composites have a much better behavior than the glass fiber reinforced polyamide matrix composites.

- The stiffness of the composites reinforced with polyamide matrix fabrics can have improvements of up to a $5 \%$, however, it is not considered an industrial scale improvement.

- Currently working with tapes materials where rigidity improvements are expected to be greater than $50 \%$.

Author Contributions: Conceptualization, resources and project administration A.P. and A.T.; formal analysis, investigation, data acquisition, writing-original draft preparation, A.P., A.T. and T.P..; writing - review and editing, all authors; funding acquisition, A.P. and M.F. All authors have read and agreed to the published version of the manuscript.

Funding: This research is funded by the InnovaPeme 2020 Program, co-financed by the European Regional Development Fund (ERDF) under the program operative Feder Galicia 2014-2020. Project: Development of a company innovation plan. Code: 046_IN848D_2020_1123865. Project in which Management Operativo 3.0 S.L., Estructuras Civiles and the Universidade de Vigo have participated.

Institutional Review Board Statement: Not applicable.

Informed Consent Statement: Not applicable.

Data Availability Statement: Data is contained within the article.

Acknowledgments: The authors would like to thank Carlos Bandrés and Maria Ulloa for their contribution in the practical work of the tests, and of course, the CTAG company, and in particular its operational injection technician Basilio Fernández for their support.

Conflicts of Interest: No potential conflict of interest was reported by the authors.

\section{References}

1. Rosato, D.V.; Rosato, M.G. Injection Molding Handbook, 3rd ed.; Springer: New York, United States, 2012.

2. Baker, A.; Dutton, S.; Kelly, D. Composite Materials for Aircraft Structures 2nd ed.; AIAA Education Series: Houston, USA, 2004.

3. Majidi, A.P.; Rotermund, M.J.; Taske, L.E. Thermoplastic preform fabrication and processing. SAMPE Journal 1988, 24 (1), $12-$ 17.

4. May, M.; Kilchert, S.; Gerster, T. A Modified Compact Tension Test for Characterization of the Intralaminar Fracture Toughness of Tri-Axial Braided Composites. Materials 2021, 14, 4890.

5. Patcharaphun, S.; Mennig, G. Properties enhancement of short glass fiber-reinforced thermoplastics via sandwich injection molding. Polym. Compos. 2005, 26 (6), 823-831.

6. Sehanobish, K. Engineering plastics and plastic composites in automotive application. 1st ed.; Society of Automotive Engineers: Warrendale, Pennsylvania, 2009.

7. Asadi, H.; Uhlemann, J.; Stranghoener, N.; Ulbricht, M. Artificial Weathering Mechanisms of Uncoated Structural Polyethylene Terephthalate Fabrics with Focus on Tensile Strength Degradation. Materials 2021, 14 (3), 618.

8. Mikołajczyk, Z.; Pieklak, K.; Roszak, A.; Knitted Meshes for Reinforcing Building Composites. Fibres \& Textiles in Eastern Europe 2019, 27, 4(136), 102-111.

9. Koutas, L. N.; Tetta, Z.; Bournas, D. A.; Triantafillou, T. C. Strengthening of Concrete Structures with Textile Reinforced Mortars: State-of-the-Art Review. Journal of Composites for Construction 2019, 23 (1), 03118001: 1-20

10. Franke, R.; Haase I.; Lehmannb,D.; Hupfer, B.; Janke, A. Manufacturing and tribological properties of sandwich materials with chemically bonded PTFE-PA 66 and PA 66/GF. Wear 2006, 262, 958-971. 
11. Marek, A.; Widdecke, H. Injection Moulding of Natural Fibre Reinforced Thermoplastics. Kunststoffe international. Available online: https://www.kunststoffe.de/en/journal/archive/article/processing-technology-with-a-future-injection-moulding-of-natural-fibre-reinforced-thermoplastics-580388.html. (Accessed: 13-Oct-2021).

12. Friedrich, K.; Almajid, A.A. Manufacturing Aspects of Advanced Polymer Composites for Automotive Applications. Appl. Compos. Mater. 2013, 20 (2), 107-128.

13. Fiorotto, M.; Lucchetta, G. Experimental investigation of a new hybrid molding process to manufacture high-performance composites. Int. J. Mater. Form. 2013, 6 (1), 179-185.

14. Khondker, O.A.; Yang, X.; Usui, N.; Nakai, A.; Hamada, H. Fabrication and mechanical properties of textile insert injection molding. ANTEC Conf. Proc. 2004, 1, 667-670.

15. Yang, X.; Usui, N.; Kitayama, T.; Matubara, S.; Nakai, A.; Hamada, H. Characterization of Knitted Fabric Reinforced PP/PP and GF/PP Composites. 64th Annual Conference of the Society of Plastics Engineers ANTEC, North Carolina, USA, 2006, 1, 5-10.

16. Martinez, A.; Castany, J.; Aisa, J. Characterization of In-Mold Decoration Process and Influence of the Fabric Characteristics in This Process. Mater. Manuf. Process. 2011, 26 (9), 1164-1172.

17. BASF PlasticsPortal - Technische Kunststoffe - Ultramid. Available online: https://documents.basf.com/e819d1d32f26cafccaaaa495da42c7fb1ec20ffc/Ultramid_Structure_Brochure_en.pdf?response-content-disposition=inline (Accessed: 17-Oct-2021).

18. Cole, G.S.; Sherman, A.M. Light weight materials for automotive applications. Mater. Charact. 1995, 35 (1), 3-9.

19. Maxwell, J. Plastics in the Automotive Industry. Woodhead Publishing, Elsevier: Cambridge, England,1994.

20. Ozkoc, G.; Bayram, G.; Bayramli, E. Effects of polyamide 6 incorporation to the short glass fiber reinforced ABS composites: an interfacial approach. Polymer 2004, 45 (26), 8957-8966.

21. Wu, H.F.; Dwight, D.W.; Huff, N.T. Effects of silane coupling agents on the interphase and performance of glass-fiber-reinforced polymer composites. Compos. Sci. Technol. 1997, 57 (8), 975-983.

22. Plueddemann, E.P. Principles of interfacial coupling in fibre-reinforced plastics. Int. J. Adhes. Adhes. 1981, 1 (6,), $305-310$.

23. Gottlieb, M.; Dvir, H. Effect of Silane Sizing on Polymer-Glass Adhesion, Proceedings of the ICCM 16th International Conference on Composite Materials, Kyoto, Japan, 2007.

24. ISO 11357-1. Plastics - Differential scanning calorimetry (DSC) - Part 1: General principles. International Organization for Standardization: Geneva, Switzerland, 2016.

25. ISO 527-4. Plastics - Determination of tensile properties - Part 4: Test conditions for isotropic and orthotropic fibre-reinforced plastic composites. International Organization for Standardization: Geneva, Switzerland, 1997.

26. Wang, G.; Zhao, G.; Wang, X. Effects of cavity surface temperature on mechanical properties of specimens with and without a weld line in rapid heat cycle molding. Mater. Des. 2013, 46, 457-472.

27. Dey, M.; Deitzel, J.M.; Gillespie, J.W.; Schweiger, S. Influence of sizing formulations on glass/epoxy interphase properties. Compos. Part A Appl. Sci. Manuf. 2014, 63, 59-67.

28. Oliveira, C.A.; Sousa, J.A. Anisotropia mecânica em moldados por injeção de compósitos de polipropileno com reforço híbrido de fibra de vidro e talco. 9ํㅡㄹ Congresso Brasileiro de Engenharia e Ciências do Materiais 2006, 2932-2943.

29. ISO 20753. Plastics - Test specimens. International Organization for Standardization: Geneva, Switzerland, 2018

30. Walther, J.; Simacek, P.; Advani, S.G. The effect of fabric and fiber tow shear on dual scale flow and fiber bundle saturation during liquid molding of textile composites. Int. J. Mater. Form. 2011, 5 (1), 83-97.

31. ISO 11339. Adhesives - T-peel test for flexible-to-flexible bonded assemblies. International Organization for Standardization: Geneva, Switzerland, 2010.

32. Shah, V. Handbook of Plastics Testing and Failure Analysis. 3rd ed.; John Wiley \& Sons Inc: New Jersey, United States, 2007.

33. ISO 6603-2. Plastics - Determination of puncture impact behaviour of rigid plastics. International Organization for Standardization: Geneva, Switzerland, 2001.

34. Nunes, J. P.; Pouzada, A S..; Bernardo, C. A. The use of a three-point support flexural test to predict the stiffness of anisotropic composite plates in bending. Polym. Test 2002, 21 (1), 27-33.

35. Wakeman, M.D.; Eble, E.; Norrey, C.; Hemnann, T.; Månson, J.-A.E. Over-injection molding of stamped thermoplastic composite textile inserts - A process and property comparison of PP and petbased materials. International SAMPE Symposium and Exhibition (Proceedings) 2005, 50, 1303-1317. 